\title{
Clímax en la relación entre sindicalismo y Derechos Humanos: La Jurisprudencia de la Corte Interamericana en materia de Derecho Colectivo del Trabajo
}

Climax in the relationship between trade unionism and Human Rights: The Jurisprudence of the Inter-American Court in matters of Collective Labor Law

Clímax na relação entre sindicalismo $e$ Direitos Humanos: a jurisprudência da Corte Interamericana em matéria de Direito Coletivo do Trabalbo

Climax dans la relation entre le syndicalisme et les droits de l'bomme: la jurisprudence de la Cour interaméricaine en matière de droit collectif du travail

在工会主义与人权之间的关系上达到顶峰: 美洲法院关于集 体劳动法的判例

\author{
Juan José Greco ${ }^{1}$ \\ Universidad Nacional de Cuyo - Argentina
}

Revista Derechos en Acción ISSN 2525-1678/ e-ISSN 2525-1686

Año 5/Nº 15, Otoño 2020 (21 marzo a 21 junio), 193-221

DOI: https://doi.org/10.24215/25251678e397

Recibido: 01/12/2019

Aprobado: 01/02/2020

\footnotetext{
Abogado por la Facultad de Derecho de la Universidad Nacional de Cuyo (2012-2019). Profesor Adscripto a la Cátedra "Derecho Administrativo II" de la Facultad de Derecho (U.N.Cuyo). Miembro del Equipo de Investigación en el Proyecto SECTYP "Empleo Público: incidencia de los tratados internacionales de Derechos Humanos". Dirigido por el Dr. Alejandro Pérez Hualde y Co dirigido por el Magister Ernesto Bustelo. (ORCID 0001-6678-7238). Correo electrónico: juanjosegreco@live.com.ar
} 
Resumen: En una serie de sentencias recientes, la Corte Interamericana de Derechos Humanos ha apuntalado el nexo entre derechos humanos y actividad sindical. Próximamente se espera que estos estándares sean sistematizados por el tribunal como respuesta a la Solicitud de Opinión Consultiva presentada en julio de 2019 por la Comisión Interamericana. Como es ilusorio suponer que todas las vulneraciones de derechos sindicales podrán tener acogida en el ámbito internacional y que en función del principio de subsidiariedad no sería adecuado, entendemos fundamental la labor de interiorización. Buena parte de la efectividad se juega en los tribunales internos.

Palabras clave: derechos humanos, actividad sindical, sistema interamericano de derechos humanos.

Abstract: In a series of recent judgments, the Inter-American Court of Human Rights has reaffirmed the link between human rights and union activity. These standards are expected to be systematized in the near future by the court in response to the Request for an Advisory Opinion presented in July 2019 by the Inter-American Commission. As it is illusory to suppose that all violations of trade union rights may be dealt with internationally and that, based on the principle of subsidiarity, it would not be appropriate, we believe that the work of internalization is essential. Much of the effectiveness is played in the domestic courts.

Keywords: human rights, union activity, interamerican human rights system

Resumo: Em uma série de julgamentos recentes, a Corte Interamericana de Direitos Humanos sustentou o vínculo entre direitos humanos e atividade sindical. Prevê-se que essas normas sejam sistematizadas em um futuro próximo pelo tribunal em resposta à solicitação de parecer consultivo apresentado em julho de 2019 pela Comissão Interamericana. Como é ilusório supor que todas as violações dos direitos sindicais possam ser aceitas internacionalmente e que, com base no princípio da subsidiariedade, não seria adequado, entendemos o trabalho de internalização como fundamental. Grande parte da eficácia é desempenhada nos tribunais nacionais.

Palavras-chave: direitos humanos, atividade sindical, sistema interamericano de direitos humanos. 
Résumé: Dans une série d'arrêts récents, la Cour interaméricaine des droits de l'homme a souligné le lien entre les droits de l'homme et l'activité syndicale. II est prévu que ces normes soient prochainement systématisées par la Cour, en réponse à la demande d'avis consultatif présentée en juillet 2019 par la Commission interaméricaine. Comme il est illusoire de supposer que toutes les violations des droits syndicaux peuvent être traitées au niveau international et que, sur la base du principe de subsidiarité, cela ne serait pas adéquat, nous considérons fundamental le travail d'internalisation. Une grande partie de l'efficacité se joue dans les tribunaux nationaux.

Mot-clés: droits de l'homme, activité syndicale, système interaméricain des droits de l'homme.

摘要: 在最近的一系列判决中, 美洲人权法院为人权与工会活动之 间的联系奠定了基础. 这些标准有望在不久的将来由法院响应美洲 委员会在2019年7月提出的征求咨询意见的要求而系统化. 幻觉地 假设所有违反工会权利的行为在国际上都可以接受, 并且基于辅助 性原则是不够的, 我们认为内部化工作是根本. 许多效力在国内法 院发挥.

关键字: 人权, 工会活动, 美洲人权制度.

\section{Introducción}

El derecho internacional de los derechos humanos ocupa un lugar preponderante en nuestro ordenamiento e irradia efectos en la gran mayoría de las parcelas en que segmentamos el fenómeno jurídico. Desde sus orígenes ha contemplado normas protectoras de la actividad sindical ${ }^{2}$.

En una serie de sentencias recientes, la Corte Interamericana de Derechos Humanos (Corte IDH) ha apuntalado el nexo entre ambos conceptos. Próximamente se espera que estos estándares sean sistematizados por el tribunal como respuesta a la Solicitud de Opinión Consultiva (OC) presentada

2 Ver por ej. Art. 23.4 de la D.U.D.H. de 1948. 
en julio de 2019 por la Comisión Interamericana (CIDH). ${ }^{3}$ Esta coyuntura sirve de pretexto para afinar la vista sobre los derechos humanos implicados en el derecho colectivo del trabajo (DCT).

La propuesta del trabajo consiste en retratar el estado de la cuestión en vísperas de la sentencia que evacúe la consulta. Su objetivo es aportar al operador jurídico un esquema sintético de la interpretación autorizada de la normativa interamericana respecto a este punto por su destacada relevancia en nuestro sistema de fuentes.

El ensayo, procurando evitar una excesiva abstracción, encuadra la jurisprudencia internacional en el ordenamiento jurídico argentino. Aun así, puede ser de provecho para quien opere el derecho en otro estado de la región, prescindiendo de los datos exclusivamente nacionales.

La metodología de exposición consiste en plantear una tipología de los derechos subjetivos comprendidos en la materia. Así, luego de clasificarlos en individuales y colectivos, se definirá cada categoría, se brindaran ejemplos y se abordará la cuestión de si tienen la jerarquía normativa de derechos humanos en Argentina. En este último punto se analizará la doctrina judicial del Tribunal de San José respecto unos y otros.

Para los primeros se sintetiza la interpretación del derecho de asociación en la Convención Americana (CADH) cuando es ejercido por trabajadoras/es en siete casos contenciosos. Para los segundos se analiza la Opinión Consultiva $\mathrm{N}^{\circ} 22 / 16$ en la que el tribunal reconoce titularidad de derechos humanos justiciables a las asociaciones sindicales. Posteriormente se aplican los métodos interpretativos del derecho internacional público a fin de adelantar sus posibles contenidos.

\footnotetext{
3 "Alcance de las obligaciones de los Estados, bajo el Sistema Interamericano, sobre las garantías a la libertad sindical, su relación con otros derechos y aplicación desde una perspectiva de género"
} 


\section{Los 'derechos' en el derecho colectivo del trabajo}

Según Etala (2007) el Derecho Colectivo del Trabajo hace referencia a las normas que regulan las relaciones plurales que se entablan entre los trabajadores y su empleador cuando los primeros defienden sus intereses colectivos (lo que incluye todo cuanto se relacione con sus condiciones laborales y de vida) (Cuartango y Cuartango, 2006).

Como se anticipó, en este estudio no se abordará el derecho colectivo de modo general sino que acotado a los derechos subjetivos que de él emanan.

En nuestro ordenamiento jurídico, en principio, puede decirse que los derechos en esta materia surgen de la Constitución Nacional (fundamentalmente del art. 14 bis), y de las leyes que reglamentan su ejercicio (art. 14 y 28 C.N.). Entre ellas cabe mencionar de modo principal a la Ley de Asociaciones Sindicales ( $\left.\mathrm{N}^{\mathrm{o}} 23.551\right)$, las leyes sobre negociación colectiva (14.250 y 23.546) y la ley sobre conflictos colectivos de trabajo (14.786). ${ }^{4}$

No obstante, no debe agotarse ahí el estudio de las fuentes legales o normativas aplicables ya que faltaría todo el aporte que tienen en esta materia los tratados internacionales, en especial los de derechos humanos en el ámbito regional. Pasar a complejizar de este modo los institutos jurídicos es parte de un proceso que ha sido llamado por la doctrina "interiorización". Es decir, lograr que los derechos reconocidos internacionalmente pasen a ser operativos para las personas en los órdenes jurídicos internos (Steiner y Uribe, 2014).

\section{Tipos de derechos subjetivos comprendidos y diversos efectos}

Los derechos colectivos del trabajo (y especialmente el derecho que constituye su núcleo -a libertad sindical-) son de

\footnotetext{
4 La doctrina identifica como contenidos del DCT la regulación legal de las asociaciones sindicales de trabajadores, la negociación colectiva, el derecho de los conflictos colectivos de trabajo, el balance social (Livellara, 2013; 785).
} 
estructura compleja ya que pueden ser individuales o colectivos (Etala, 2007; 63) 5 pero siempre derechos colectivos del trabajo. La diferencia está dada por quién sea el sujeto titular de las libertades, inmunidades y privilegios que otorgan.

La idea es utilizar esta distinción analítica como categoría para comprender mejor unos y otros, su diverso contenido y sus -también disímiles- efectos.

En este punto, las preguntas que se sometieron a escrutinio fueron las siguientes: ¿la diferencia también importa diferente intensidad en la tutela? ¿Ambas categorías pueden ser consideradas "derechos humanos"? La respuesta de la primera pregunta estará - en cierta medida - subordinada a la respuesta de la segunda ya que una contestación afirmativa los blindará con la máxima jerarquía que les otorga nuestro ordenamiento y - eventualmente- mecanismos de protección adicionales.

\section{Derechos individuales}

\subsection{Concepto}

Estos son titularizados por la persona trabajadora considerada aisladamente. Entre ellos puede mencionarse: el derecho de constituir asociaciones, adherirse a una constituida, participar en sus actividades, elegir a sus representantes.

Al ejemplificar se omitió mencionar el derecho de huelga. Esto es así porque la CSJN en el caso "Orellano" (2016) lo encasilló como un derecho de titularidad exclusivamente colectiva (tratados más adelante) y por lo tanto consideró ilegítima la huelga llevada a cabo por trabajadores/as cuando la misma no ha sido convocada por una asociación sindical. ${ }^{6}$

\footnotetext{
5 Nuestra Ley de Asociaciones Sindicales realiza una distinción similar en sus arts. $4^{\circ}$ y $5^{\circ}$. El Tribunal Constitucional Peruano identifica tres dimensiones cfr. Hancco Suyo, 2019; p. 839.

6 Para una crítica exhaustiva de esta interpretación restrictiva ver ZAS, 2017.
} 


\subsection{Estatus jurídico: ¿son derechos humanos?}

Nuestra Constitución Nacional desde 1957 manifiesta la existencia de derechos sindicales individuales estableciendo, en el primero de los tres bloques del artículo 14 bis, el deber de asegurar al trabajador organización sindical libre y democrática.

Esto se ve reforzado en la reforma del año 1994 por haberle otorgado jerarquía constitucional a numerosos tratados internacionales de derechos humanos que le dan una amplia acogida al derecho de asociación. ${ }^{7}$

\subsection{Los derechos sindicales individuales en la jurisprudencia de la Corte IDH}

En la región, la Corte IDH ha declarado violado el art. 16 de la CADH (Libertad de Asociación) en varias oportunidades en contexto de conflicto colectivo del trabajo. Se sistematiza toda la jurisprudencia sobre el tema analizando siete casos contenciosos comprendidos en el periodo 2001-2019 seguidos contra Panamá, Perú (en tres oportunidades), Guatemala (en dos) y Colombia. ${ }^{8}$

En todos los casos se trata de conculcación del derecho a personas individualmente consideradas: ya sea por las represalias laborales tomadas por el empleador ante el ejercicio de derechos sindicales (p.ej. Corte IDH, Lagos del Campo c. Perú, 2017) o por la vulneración a derechos civiles (la vida, por ejemplo) por su actividad sindical (p. ej. Corte IDH, Huilca Tecse c. Perú, 2005).

Reza el artículo 16.1: "Todas las personas tienen derecho a asociarse libremente con fines ideológicos, religiosos, políticos, económicos, laborales, sociales, culturales, deportivos o de cualquiera otra índole" (subrayado añadido).

\footnotetext{
7 Por mencionar algunos casos: art. 20 de la Declaración Universal de Derechos Humanos, art. 22 de la Declaración Americana de Derechos y Deberes del Hombre. (Art. 75 inc. 22)

8 Puede confrontarse esta sistematización con la realizada por Hancco Suyo (2019) que reflexiona sobre cuatro de los pronunciamientos. El autor resume la plataforma fáctica de los casos, lo que aquí se omite en honor a la brevedad.
} 
Sobre el carácter del derecho aquí reconocido, y en consonancia con la tipología propuesta, dice la Corte IDH: "quienes están bajo la protección de la Convención tienen (...) el derecho y la libertad de asociarse libremente con otras personas, sin intervención de las autoridades públicas que limiten o entorpezcan el ejercicio del respectivo derecho, lo que representa, por lo tanto, un derecho de cada individuo." (Huilca Tecse c. Perú, 2005; párr. 69) (subrayado añadido).

En los casos de implicación de derecho colectivo del trabajo la Corte ha entendido que el contenido de la libertad sindical es una de las formas de (está contenida en) la libertad de asociación. (García y Familiares c. Guatemala, 2012; párr.117 y Isaza Uribe c. Colombia, 2018; párr. 145) Textualmente ha dicho “... (al) considerar si se configuró o no en el caso en cuestión la violación de la libertad de asociación, ésta debe ser analizada en relación con la libertad sindical (Baena c. Panamá, 2001; párr. 156).

Así entendida, para la Corte, esta libertad reviste la mayor importancia para la defensa de los intereses de los trabajadores y conforma el corpus iuris de los derechos humanos (Ídem; párr. 158).

Sobre la titularidad del derecho, el estándar interamericano no exige que se goce del carácter de dirigente o representante ya que en un contexto de violencia hacia los sindicatos la mera afiliación o simpatía son suficientes para gozar de protección (Corte IDH, Isaza Uribe c. Colombia, 2018; párr. 138). Así mismo no es necesario para gozar de la protección en el contexto laboral de que se trate de un sindicato ya que se extiende igualmente a "organizaciones de otra naturaleza que representen los intereses de las y los trabajadores" (Corte IDH, Lagos del Campo c. Perú, 2017; párr. 158).

Avanzando sobre el contenido, este derecho tiene un aspecto negativo consistente en la libertad de no pertenecer a un sindicato si no se lo desea y positivo "constituir organizaciones sindicales y poner en marcha su estructura interna, actividades y 
programa de acción, sin intervención de las autoridades públicas que limite o entorpezca el ejercicio del respectivo derecho" (Ídem; Párr. 156).

Dice la Corte "en materia laboral, no se agota con el reconocimiento teórico del derecho a formar sindicatos, sino que comprende además, inseparablemente, el derecho a utilizar cualquier medio apropiado para ejercer esa libertad." (Huilca Tecse c. Perú, 2005; párr. 70). Aquí cobra relevancia el pasaje del art. que se refiere a los fines tenidos en cuenta para asociarse. Para la CADH la libertad de asociarse y perseguir fines colectivos son indivisibles: una intromisión en un medio legítimo a través del cual se manifiesta el derecho a sindicarse impide cumplir los fines perseguidos.

Por lo tanto dice la Corte: (mensaje trascendental al legislador) el régimen legal de los sindicatos (y al administrador) y las acciones llevadas a cabo o toleradas por el Estado respecto de estos deben adecuarse a la Convención (Ibídem).

La Corte ha identificado dos dimensiones del derecho de asociación que deben ser garantizadas simultáneamente: la individual y la social. En ciertos casos acciones u omisiones estatales pueden afectarlas simultáneamente. La individual: consiste en asociarse libremente y utilizar los medios apropiados para ejercer esa libertad. La social: implica el derecho de los integrantes de un grupo para alcanzar determinados fines en conjunto y beneficiarse de los mismos (Huilca Tecse c. Perú, 2005; párr. 70 a 72 y Lagos del Campo c. Perú, 2017 párr. 162).

El Tribunal, siguiendo al Tribunal Europeo de Derechos Humanos, establece que el derecho del art. 16 no se limita a crear una obligación negativa de no interferir, sino por el contrario debe tomar las acciones positivas -incluso en la esfera entre particulares- para garantizar que las personas puedan ejercer sin miedo su libertad sindical. Esto reforzará la posibilidad de las asociaciones de organizarse por sus intereses (dimensión social) (Huilca Tecse c. Perú, 2005; párr. 77 y García y Familiares c. Guatemala, 2012; párr.117). 
Acciones toleradas por el estado que afecten otros derechos a un dirigente sindical (por ejemplo la vida, la integridad) puede amedrentar al conjunto de los trabajadores, limitando su libertad sindical y lesionando el derecho de asociación (en su dimensión social). Evitar la tolerancia exige, por ejemplo, diligencia en la investigación de crímenes contra dirigentes sindicales (Corte IDH, Cantoral Huamaní y García Santa Cruz c. Perú, 2007; párr. 146). Se entiende que quien exhorte a las autoridades a investigar y sancionar un crimen con motivo sindical (por ejemplo un querellante) podrá invocar estas consideraciones para exigir especial cuidado e impulso en las actuaciones. En caso de acciones cometidas por particulares, para que surja la obligación del estado de prevenir se requiere conocer(o deber conocer) la existencia de un riesgo real e inminente para un individuo o grupo determinado e implica adoptar medidas razonables para evitar el daño (Corte IDH, 2019 Gómez Virula c. Guatemala) ${ }^{9}$.

En un caso dijo "(las ejecuciones) no restringieron sólo la libertad de asociación de un individuo, sino también el derecho y la libertad de un grupo determinado para asociarse libremente sin miedo o temor, es decir, se afectó la libertad de los trabajadores (mineros) para ejercer este derecho" (Corte IDH, Cantoral Huamaní y García Santa Cruz c. Perú, 2007; párr. 148) ${ }^{10}$ (subrayado añadido).

Si bien en principio pareciera claro que estamos hablando de un derecho individual de corte clásico (libertades burguesas o de primera generación), su particular característica en el

9 Dice: "Este estándar ha sido aplicado (...) en situaciones de desaparición de mujeres ocurridas dentro de un contexto de aumento de violencia homicida contra mujeres, e igualmente sería aplicable dentro de un contexto de aumento de violencia homicida contra sindicalistas (párr. 56).

10 Dice la Corte en Lagos del Campo, párr. 162: “Este derecho tiene naturaleza dual: pues recae tanto en el derecho del individuo que ejerce el mandato o designación como en el derecho de la colectividad de ser representada, por lo que la violación del derecho del primero (el representante) repercute en la vulneración del derecho del otro (el representado). 
ámbito laboral, su dimensión social, le da connotaciones que trascienden a los sujetos aisladamente considerados. ${ }^{11}$

Hasta aquí se ha ejemplificado con violaciones a derechos civiles que al tener como objetivo impedir el ejercicio de la libertad de asociación configura una violación autónoma de esta. ${ }^{12}$ Sin embargo los trabajadores y las trabajadoras sindicalizadas/os deben contar también con protección en el ámbito laboral por ejemplo contra el despido por su condición. Del mismo modo debe escrutarse con rigor la sanción que por motivo laboral se le imponga a un representante ya que de ser desproporcionada tendrá efecto disuasor en sus compañeras/os para arrojarse a la defensa de sus intereses (nuevamente la dimensión social) (Corte IDH, 2017 párr. 160).

Como todos los derechos el de asociación no es absoluto. En cada caso se debe analizar si las restricciones al derecho llevadas a cabo por los estados están previstas por la ley, son necesarias en una sociedad democrática, y que se establecen en interés de la seguridad nacional, del orden público, de la salud o de la moral públicas o de los derechos o libertades de los demás. ${ }^{13}$ Por el contrario implicaran una intervención arbitraria.

\section{Derechos Colectivos}

\subsection{Concepto}

El titular del derecho será en este caso la organización (como persona jurídica diferente a sus miembros: art. 143 del

\footnotetext{
11 En realidad podría ser tenido como un buen ejemplo de los derechos que ponen en cuestión ese tipo de divisiones. Para una crítica a la teoría de generaciones de derechos ver Bazán, 2011. Hancco Suyo (2019;852) dice que la libertad sindical es un derecho social que también es considerado civil.

12 Por otro lado es una posición sostenida por el Comité de Libertad Sindical OIT, 2018 Cap. II.

13 Art. 16.2 CADH. Estos criterios son tenidos en cuenta por nuestra Corte. Por ejemplo CSJN, A.T.E. c. Min de Trabajo, 2008; Cons. 9).
} 
Código Civil y Comercial.) Son las asociaciones u organizaciones conformadas por los trabajadores y las trabajadoras, reguladas fundamentalmente en nuestro ordenamiento por la ley 23.551 .

Entre ellos se puede mencionar: la facultad de autodeterminación de las asociaciones sindicales (cuyo contenido es muy amplio), el derecho a participar en la negociación colectiva, el derecho de huelga-para la CSJN-, etc.

\subsection{Estatus jurídico: ¿son derechos humanos?}

En principio rápidamente se podría decir que varios de ellos integran la Constitución. El segundo bloque de derechos del art 14 bis reconociendo a los gremios la garantía de: concertar convenios colectivos, el derecho de buelga, las garantías para cumplir su función a los representantes, etc.

Siendo derechos constitucionales, ¿son además derechos humanos en sentido estricto? Una investigación sobre el régimen jurídico de los sindicatos bajo la perspectiva de derechos humanos: ¿debe solo centrarse en el derecho del empleado a asociarse y a ejercer sus derechos asociativos o debe mirar también las prerrogativas de la asociación como persona de existencia ideal? Lo cual lleva a un tema debatido arduamente: ¿pueden las personas jurídicas titularizar derechos humanos?

La respuesta es sí (en este caso sí) por dos motivos.

El primero, bastante evidente, y es que estos derechos así están contemplados por "tratados y convenciones sobre derechos humanos" (como se refiere a ellos el art. 75 inc. 22). Por ejemplo, El Pacto Internacional de Derechos Económicos, Sociales y Culturales, en el art. 8.1 C dice "el derecho de los sindicatos a funcionar..."

El segundo motivo tiene que ver con una decisión de la Corte IDH que hace de lleno al objeto de estudio del presente trabajo y se analizará a continuación. 


\subsection{Las asociaciones sindicales como titulares de DDHH en el SIDH}

\subsubsection{Opinión Consultiva $\mathrm{N}^{\mathrm{o}} 22 / 16$}

Tras el sólido argumento anterior lo cual le da un blindaje dogmático importante a los derechos sindicales, es pertinente preguntarse ¿sigue teniendo importancia saber si titularizan derechos en el Sistema Interamericano de Derechos Humanos (SIDH) y por lo tanto tienen legitimación activa en el mismo? Creo que la respuesta es, nuevamente, sí. Sobre la importancia de contar con este mecanismo extra de protección me explayaré más adelante, fundando primero por qué pueden aquí incluirse.

La pregunta es: ¿están amparados los derechos sindicales de índole colectiva en el SIDH? la que remite a una cuestión anterior y es ¿las personas jurídicas pueden ser titulares de los derechos que establece la $\mathrm{CADH}$ y por lo tanto pueden acceder de forma directa al SIDH como presuntas víctimas?

Esta última cuestión se le formuló a la Corte IDH en su función Consultiva quien se expidió a través de la OC $\mathrm{N}^{\circ} 22 / 16$ titulada "Titularidad de derechos de las personas jurídicas en el sistema interamericano de derechos humanos."

La Corte, luego de interpretar la $\mathrm{CADH}$ por los distintos medios que establece la "Convención de Viena sobre el Derecho de los Tratados" en sus artículos 31 y 32, concluyó que el artículo 1.2 de la Convención Americana no atribuye a las personas jurídicas la titularidad de derechos reconocidos en la Convención, sin perjuicio de la denominación que estas reciban en el derecho interno de los Estados tales como cooperativas, sociedades o empresas.

La primera consecuencia que se deriva es que las personas jurídicas al no ser titulares de derechos convencionales, no pueden ser consideradas como presuntas víctimas en el marco de los procesos contenciosos ante el Sistema.

Entre otros argumentos la Corte de San José apela a la interpretación literal de los términos y recuerda que el texto 
analizado no dejó a la libre interpretación que se entiende por persona si no que la definió claramente: "Para los efectos de esta Convención, persona es todo ser humano" (Art. 1.2).

No obstante este artículo, la Corte se hace cargo de otras disposiciones presentes en el "corpus iuris" del derecho internacional de los derechos humanos aplicable para establecer dos excepciones para ciertas categorías de colectivos que sí gozarán de protección en las Américas:

i. En primer lugar se refiere a las comunidades indígenas y tribales:

Remite a su jurisprudencia anterior donde además de declarar violados los derechos de miembros de la comunidad declara violados los derechos de la comunidad misma.

Aquí funda la decisión en que existe normativa internacional (como el convenio 169 de la Organización Internacional del Trabajo-OIT-) que declara a las comunidades como sujetos colectivos de derecho internacional. Cuestión que es coherente con el modo cohesionado que tienen los pueblos de ejercer sus derechos que es consecuencia de su identidad y cosmovisión. Así una afectación a estos derechos siempre tendrá una repercusión que excede lo individual (Corte IDH, 2016; párr. 72 a 84$)$.

ii. La segunda excepción y la que aquí interesa es la que hace la Corte respecto a: sindicatos - federaciones y confederaciones.

El tribunal funda normativamente este caso en el Protocolo adicional a la C.A.D.H. en materia de Derechos Económicos Sociales y Culturales (DESC) - en adelante Protocolo de San Salvador -ratificado por nuestro país mediante ley 24.658, depositando el instrumento ratificatorio en el año 2003-.

En su art. 19.6 el protocolo habilita el procedimiento de peticiones y casos previsto en la $\mathrm{CADH}$ para los derechos protegidos en el art. 13 (derecho a la educación) y para el art. 8 párrafo (a que reza: 
“1. Los Estados partes garantizarán:

a. el derecho de los trabajadores a organizar sindicatos y a afiliarse al de su elección, para la protección y promoción de sus intereses. Como proyección de este derecho, los Estados partes permitirán a los sindicatos formar federaciones y confederaciones nacionales y asociarse a las ya existentes, así como formar organizaciones sindicales internacionales y asociarse a la de su elección. Los Estados partes también permitirán que los sindicatos, federaciones y confederaciones funcionen libremente" (subrayado añadido).

Aquí el tribunal -luego de aclarar que no ha decidido aún casos sobre este artículo- se cuestiona si lo que hace el tratado es reconocer derechos subjetivos en cabeza de los sindicatos o simplemente refuerza los de los trabajadores individualmente considerados.

Tras aplicar los métodos ya nombrados postula:

- Que cuando el tratado dice "como proyección de este derecho" lo que hace la norma es darle al derecho reconocido a los trabajadores un medio de protección específica: la existencia de una persona diferente a la de sus miembros que funciona como interlocutor para la defensa de sus derechos. Para que este mecanismo (el sindicato) sea efectivo lo instituye como sujeto de derecho (párr. 92).

- El enunciado "permitirá que se asocien y funcionen libremente" es el deber del Estado de garantizar hacer posible esos actos. Reconocer esta capacidad de actuar a la asociación presupone que tiene personalidad jurídica (párr. 91).

- El título mismo del art. es "derechos sindicales" y la Corte, realizando una distinción similar a la realizada precedentemente, dice que es una denominación que abarca tanto los derechos de los trabajadores individuales (constituir y afiliarse) y de la persona jurídica (asociarse a su vez y funcionar libremente) (párr. 93). 
La conclusión es que el artículo 8.1.a del Protocolo de San Salvador otorga titularidad de derechos a los sindicatos, las federaciones y las confederaciones. Recientemente, obiter dictum, reiteró esta posición (Corte IDH, Lagos del Campo 2017; párr. 157).

En vistas a ser una novedad jurisprudencial absoluta ${ }^{14}$ y no existir aún casos resueltos aplicando su doctrina, las proyecciones autorales que se hagan de la misma pueden ser interesantes pero deben ser cautelosas. Esto último, máxime teniendo en cuenta el voto parcialmente disidente del juez Alberto Pérez Pérez que en lo relativo a las asociaciones sindicales entiende que no se fundó adecuadamente, fue temerario decidir sobre disposiciones no analizadas en ejercicio de la competencia contenciosa del tribunal y que se debió oír a la OIT sobre el punto en cuestión (Corte IDH, 2016, Capítulo V del voto parcialmente disidente del Juez Pérez Pérez).

\subsubsection{Efectos de la doctrina sentada por la Corte IDH}

El primer y fundamental efecto es la existencia de un mecanismo de tutela adicional. Concretamente: los sindicatos pueden presentarse como presuntas víctimas al SIDH. Esto abarca sus distintas competencias:

- Competencia Contenciosa: es decir en casos en que se vulnere un derecho colectivo y fracase la protección a nivel local, pueden presentar una petición a la Comisión IDH. Por lo tanto a los mecanismos de la OIT se suma un nuevo ámbito internacional de tutela, en este caso el SIDH.

\footnotetext{
14 Hasta esta sentencia la postura consolidada por el tribunal era que las personas jurídicas no han sido consideradas por la CADH, sin embargo "esto no restringe la posibilidad de que bajo determinados supuestos el individuo pueda acudir al Sistema Interamericano de Protección de los Derechos Humanos para hacer valer sus derechos fundamentales, aun cuando los mismos estén cubiertos por una figura o ficción jurídico(....)." El análisis que se llevaba a cabo era si se habia ejercido un derecho protegido a través de la persona jurídica. Corte IDH. Caso Granier y otros (Radio Caracas Televisión) Vs. Venezuela. Excepciones Preliminares, Fondo, Reparaciones y Costas. Sentencia de 22 de junio de 2015.
} 
- Competencia Preventiva: los sindicatos podrían solicitar medidas cautelares ante la CIDH. Es decir buscar una tutela aun sin agotar los recursos internos o reunir los otros requisitos de una petición (e independientemente de estar o no tramitándola). El art. 25 del reglamento de la Comisión exige para ello "daño irreparable a las personas" que además de ser todo ser humano, pienso, podrán ser las comunidades indígenas y los sindicatos. Deberán reunirse, como en cualquier medida cautelar, los extremos de gravedad y urgencia.

La posibilidad de que los sindicatos puedan acudir al SIDH es especialmente relevante si tenemos en cuenta que las decisiones de la Corte IDH son vinculantes para los estados parte y así lo ha sostenido la Corte Suprema de Justicia de la Nación Argentina. ${ }^{15}$

Además el tribunal internacional tiene una sostenida doctrina sobre el "control de convencionalidad". Impone que cualquier autoridad pública local (incluido el poder judicial) se encuentra obligada a realizar, de oficio, un control de convencionalidad (es decir, un análisis de compatibilidad), en el marco de su respectiva competencia y las regulaciones procesales, entre la $\mathrm{CADH}$ (y otros tratados vinculantes) y las normas y prácticas internas teniendo en cuenta las interpretaciones realizadas por la Corte IDH. Este control puede implicar el deber de: expulsar normas, expedir leyes, de realizar una interpretación conforme, etc. ${ }^{16}$

\footnotetext{
15 Esta fue la doctrina consolidada por la CSJN, con claridad, hasta el año 2017. Para apuntalar esta enunciación pueden consultarse los siguientes fallos. En casos donde Argentina fue demandado ante el SIDH: "Espósito" (2004). En casos en que la República no fue parte en el proceso internacional pero la Corte igual aplico la doctrina que emana del precedente: "Simon"(2005), "Lociser "(2012). Si bien alguna doctrina entendió que esto fue puesto en crisis con la sentencia del 14 de febrero del 2017 "Fontevecchia", la Corte Nacional ha continuado acatando pronunciamientos internacionales, por ejemplo en Sala, Milagro", 2017. La Corte continúa recurriendo a la jurisprudencia de la Corte IDH al interpretar derechos fundamentales, incluso sindicales (CSJN, 2019). Los efectos de la doctrina de Fontevecchia no implican una desautorización al SIDH. Indudablemente este tema habilita un trabajo autónomo, sin embargo por los efectos sobre nuestro objeto de estudio era imperioso este excurso.

16 Corte IDH. Cuadernillo de jurisprudencia de la Corte Interamericana de Derechos Humanos $N^{0}$ 17: Control de convencionalidad. Disponible en: http://www.corteidh.or.cr/sitios/libros/ todos/docs/cuadernillo7.pdf revisado por ultima vez el 24 de mar. de 2020.
} 
El efecto de este instituto es que los desarrollos que sobre estos derechos realice el tribunal deberían irradiar efectos en nuestro ordenamiento jurídico, independientemente de si el demandado es el Estado Argentino.

3.3.3. Contenido del derecho: perspectivas en vísperas a la respuesta a la OC solicitada por la CIDH.17

Ante la amplitud de la formulación de los derechos que titularizan los sindicatos en el Pacto de San Salvador (propia de un tratado internacional) cabe introducirse al análisis de su contenido, proponiendo posibles lineamientos a confrontar con la sentencia que responda la solicitud de opinión.

El art. 8.1 se refiere al derecho de: "constituir asociaciones de segundo y tercer grado y a funcionar libremente." Voy a centrarme en el segundo derecho.

En la práctica de la Corte IDH ya se han presentado situaciones donde debe completar el contenido de una norma del tratado para el que es competente. Siguiendo su ejemplo podemos hipotetizar sobre el resultado, no exhaustivo, de aplicar los siguientes métodos interpretativos:

- En primer lugar apelando al sentido corriente de los términos: la misma Corte en la OC (párr.91) establece que una asociación sindical funcione libremente por supuesto incluye "crear sus propios estatutos, elegir a sus representantes o manejar sus finanzas" y todas aquellas que sean la proyección del derecho de los trabajadores a promover sus intereses (art. 8.1 primera parte). Lo cual desecha una mirada restrictiva de la incumbencia sindical limitada al acuerdo salarial y lo amplía por ejemplo al aspecto social del trabajo, incorporando cuestiones como el ambiente

\footnotetext{
17 Por razones de extensión no se abordara aquí- como sería deseable- el sustrato fáctico sobre el que se aplicará la normativa a interpretar. Sobre el particular ver Capítulo III del escrito la Comisión solicitando la OC, presentando su mirada sobre el estado de situación del sindicalismo en las Américas. (CIDH, 2019). Una propuesta donde se considera relevante relevar el marco fáctico (Greco, 2019).
} 
laboral y la salud de las y los trabajadores. ${ }^{18}$ Una exegesis razonable de "funcionar libremente" se enlaza rápidamente con uno de los principios liminares en materia sindical: la no injerencia por parte de los empleadores. ${ }^{19}$ El derecho de huelga (art.8.1.b), si bien en principio parece incluido en el funcionamiento libre de un sindicato, está excluido de la competencia contenciosa por el Protocolo (que contempla solo el inc. 1.a del art. 8). En ese sentido Corte IDH, 2016; párr. 104.

- Una interpretación que tenga en cuenta el sistema al cual pertenece la norma debe considerar que, como todo derecho humano, está caracterizado por la universalidad, indivisibilidad, integralidad e interdependencia (Wlasic, 2006). Por tratarse de un derecho de los clasificados como Económicos, Sociales y Culturales(al menos por el texto que lo contiene) cobra especial interés el principio de progresividad con sus dos sentidos: gradualidad y progreso. De esta última se deriva la obligación mínima para los estados de prohibición de regresividad (Christian Courtis, 2006). Debe apuntarse que en los últimos años se ha producido una interesante aceleración en la justiciabilidad de DESC por parte de la Corte de San José (Mac-Gregor y otras, 2018; 374). ${ }^{20}$

- De una interpretación evolutiva, que consiste en considerar que los tratados de derechos humanos son instrumentos vivos cuya interpretación tiene que acompañar la evolución de los tiempos y las condiciones de vida actuales, se deriva:

i. La posibilidad de recurrir a otros instrumentos de derechos humanos para fijar el alcance de una norma - p. ej. así lo ha realizado la Corte IDH recurriendo a la Convención sobre los

18 Este enfoque amplio es sostenido respecto del contenido de la negociación colectivo en Cabral y Schreginger, 2009; 454y ss.

19 Un acto de injerencia sería el fomento a la creación de organizaciones sindicales paralelas controladas por los empleadores (Livellara, 2013; 795).

20 Para una recapitulación de los últimos casos ver nota 230 en Corte IDH, 2019 donde la Corte declara justiciable el derecho a la seguridad social. 
Derechos del Niño de la ONU para fijar las "medidas especiales de protección" a las que genéricamente se refiere la CADH. Por ejemplo en el emblemático caso "Niños de la Calle" (Villagrán Morales c. Guatemala, 1999).

En este caso es evidente que el corpus iuris del derecho sindical está compuesto en gran medida por la normativa que emana de la OIT. Existen numerosos precedentes en los que el tribunal utiliza normativa del organismo tripartito. Se ha citado el Convenio $\mathrm{N}^{\circ} 182$ (sobre las peores formas de trabajo infantil: "Vargas Areco c. Paraguay, 2006" y "Trabajadores de la Hacienda Brasil Verde c. Brasil, 2017", el Convenio No 29 (sobre el trabajo forzoso): "Masacre de Ituango c. Colombia, 2006" y el Convenio $\mathrm{N}^{\mathrm{o}} 169$ (sobre pueblos indígenas y tribales): entre numerosísimos "Caso de la Comunidad Mayagna (Sumo) Awas Tingni Vs. Nicaragua, 2001" y "Caso Pueblo Indígena Kichwa de Sarayaku Vs. Ecuador, 2012.” En materia específica de sindicatos en el sector público es insoslayable remitirse al Convenio $\mathrm{N}^{\circ} 151$ de la OIT "sobre las relaciones de trabajo en la administración pública".

Además en el ámbito Americano existen normas que completaran los textos de referencia tales como la Carta de la OEA ${ }^{21}$ y la Carta Internacional Americana de Garantías Sociales ${ }^{22}$.

ii. Además en su labor de fijar los alcances de un precepto recurriendo a otros instrumentos, no se limita a la letra del tratado sino que apela a las interpretaciones que del mismo hace el órgano especializado. Este procedimiento puede verse en numerosos casos, por citar un ejemplo puede verse "González LLuy c. Ecuador, 2015" Allí al establecer el contenido del derecho a la integridad personal (art. 5.1 CADH) relacionado a la salud, citó al Comité de Derechos Económicos Sociales y Culturales que en su Observación General No 14 (El derecho al disfrute del nivel más alto posible de salud).

21 Sin duda art. 45 c):derechos de huelga, asociación, personería jurídica, etc. http://www. oas.org/es/sla/ddi/tratados_multilaterales_interamericanos_A-41_carta_OEA.asp

22 Art. 26 y 27 derecho de asociación y huelga. http://www.derechoshumanos.unlp.edu.ar/ buscador/search/printlnstrumento/34 
Adelantándose a estas conjeturas, en la OC comentada, al fijar la capacidad de los sindicatos la Corte (párr. 102) cita el Convenio N $^{\circ} 87$ y al Comité de Libertad Sindical: para anticipar que los estados tienen la obligación negativa de abstenerse de crear barreras jurídicas o políticas para que los sindicatos ejerzan sus derechos y obligaciones positivas de crear las condiciones para que ese ejercicio sea posible. Siempre llenando el significante "derechos" con las prerrogativas del Convenio 87 (instrumento que ha sido utilizado por nuestra CSJN) ${ }^{23}$.

Todo esto realza la tutela que brinda la OIT a los sindicatos ya que no se agota exclusivamente en el acatamiento que sus decisiones reciban por parte de los Estados sino que se yergue como fuente de derecho del SIDH.

iii. Una fuente recurrente de la Corte IDH es la argumentación comparada de la mano del Tribunal Europeo de Derechos Humanos (TEDH). La Gran Sala en Demir y Baykara c. Turquía ${ }^{24}$ ya tuvo la oportunidad de declarar responsabilidad internacional por la anulación de un Convenio Colectivo firmado por un estado y un gremio de municipales. Lo hizo tras citar convenios y pronunciamientos de la OIT.

Una situación que podría generar dudas es el principio hermenéutico fundamental en materia de $\mathrm{DDHH}$ el principio antiguamente llamado "pro homine" y hoy "pro persona" ¿la interpretación más garantista es solo para personas humanas? La misma Corte desecha esta posibilidad en la OC bajo análisis al utilizar el principio pro persona como uno de los argumentos en los que apuntala el reconocimiento de derechos a los sindicatos en América.

\footnotetext{
23 Por ejemplo en el caso A.T.E. c. Min. de Trabajo del 11 de noviembre de 2008. La doctrina entiende que según la jurisprudencia de la CSJN de asignarle a "en las condiciones de su vigencia" al art. 75 inc 22 el significado de que los tratados rigen en las condiciones de aplicación de los organismos externos especializados cobran interés los pronunciamientos de dicho comité y de la Comisión de Expertos en la Aplicación de Convenios y Resoluciones de la OIT (MACHADO y OJEDA, 2006; 228).
}

24 DEMIR AND BAYKARA v. TURKEY - 34503/97 [2008] ECHR 1345 (12 November 2008) 
Otra cuestión que genera dudas interpretativas es si es un requisito para acceder como persona jurídica (sindicato) al sistema de peticiones y casos del SIDH el tener la personería reconocida por el estado demandado. Se trata de pulir y clarificar la competencia ratione personae respecto de la presunta víctima ${ }^{25}$.

Sobre este punto es interesante observar la práctica del Comité de Libertad Sindical. Al decidir sobre la admisibilidad de las quejas que se le presentaran, el Comité goza de entera libertad para analizar si quien se presenta tiene el carácter de organización de trabajadores en los términos de la Constitución de la OIT, no encontrándose ligada por la definición legal del país. Del mismo modo es indiferente si el Estado ha disuelto la asociación o no le brinda reconocimiento oficial siempre y cuando goce de existencia de hecho (OIT, 2018; p. 318).

Posiblemente de modo análogo la Corte determinará cuándo estamos en presencia de un sindicato para el derecho interamericano, aunque no lo sea para el derecho estatal.

Sería interesante que la Corte fijara algunas modulaciones a los estándares cuando se trate de sindicatos que aglutinan trabajadoras/es del sector público. ${ }^{26} \mathrm{El}$ marco de su desenvolvimiento presenta particularidades (por un lado la estabilidad de la que suelen/deberían gozar los agentes, las necesidades de continuidad del servicio pero por otro: la precariedad en el empleo público, el carácter simultáneo de empleador y titular del poder de policía laboral, etc.) (Greco, 2019). Específicamente, una directiva interpretativa sobre el derecho al debido proceso y a un recurso efectivo debería exhortar a los tribunales a flexibilizar los criterios de acceso a la justicia en estos casos para garantizar la intervención de un tercero imparcial. En la misma inteligencia fijar un criterio estricto al juzgar

\footnotetext{
25 Para ampliar sobre la competencia en razón de la persona y sus tres aristas (demandado, denunciante, presunta víctima) ver por ejemplo: Fauendez Ledesma, 1999; 200.

26 Al solicitar la opinión la CIDH solicita tener en cuenta “la naturaleza y condición del órgano empleador" (CIDH, 2019; Párr 69.a)
} 
la potestad disciplinaria y reglamentaria sobre empleo público que puedan tener como consecuencia efectos antisindicales. ${ }^{27}$

En la Solicitud de OC la CIDH pide atinadamente que se escrute el marco normativo con perspectiva de género. ${ }^{28}$ Con seguridad este punto justifica un trabajo autónomo y será esencial tomar en cuenta las observaciones que los colectivos feministas presenten al Tribunal. Por lo pronto se hará una observación crítica a la formulación de la Solicitud por parte de la Comisión y se formularan posibles desarrollos interpretativos con carácter de hipótesis exploratoria.

En primer lugar la Comisión parece concentrarse excesivamente en las asimetrías en el mercado del trabajo y en el goce de derechos laborales en perjuicio de las mujeres ${ }^{29}$, soslayando los sindicales. Si bien con seguridad una de las causas de la situación laboral esté en el desigual acceso a derechos sindicales, entiendo que hubiera sido deseable ahondar más en estos (objeto de la solicitud). ${ }^{30}$ Además si se realza el rol de los derechos sindicales como mecanismo para posibilitar los derechos laborales, no podemos luego olvidarlos y centrarnos solo en estos últimos.

En consecuencia sería importante que la Corte se centre en los estándares interamericanos que permitan un goce en

\footnotetext{
27 A modo de ejemplo: la conformación del salario con el pago de un adicional por la presencia efectiva en el lugar de trabajo que se le niegue a un delegado gremial en uso de licencia sindical legal.

28 La perspectiva de género importa “Reconocer las relaciones de poder entre los géneros, que imponen un acceso diferencial a recursos materiales y simbólicos a partir de la jerarquización de los varones sobre las mujeres", "Partir del carácter de construcción social e histórica de tales relaciones y por ende, la posibilidad de su transformación" Reflexionar sobre las múltiples formas de opresión que atraviesan el entramado social" como la clase 0 la etnia (González Prado y Yanes, 2013; 219).

29 Por ejemplo: diferente tiempo dedicado al trabajo no remunerado (párr. 61) o brecha salarial (párr.65), etc.

30 En realidad la abundancia de datos y reflexiones hacen pensar en que sería deseable consultar a la Corte específicamente sobre materia laboral. Lo que no sería inoportuna teniendo en cuenta que la Corte IDH (2017) la consideró justiciable a través del art. 26 de la CADH.
} 
condiciones de igualdad real a las mujeres en lo sindical (al menos hasta una futura OC específica sobre derechos laborales). Solo existe una mención a que en el ámbito laboral en general y en el contexto sindical específicamente se refleja la "discriminación y exclusión histórica a la que han sido sometidas las mujeres" (CIDH, 2019; párr. 59). Al acompañar datos no es tan prolífica como respecto al trabajo: en un párr. (67) se limita a indicar la desigual tasa de participación en los sindicatos y en las dirigencias. La legislación argentina establece un cupo del $30 \%$ de representación femenina en la dirigencia (ley 23.551 modificada por ley 25.674). ${ }^{31}$

La proporción de mujeres que participan de la negociación colectiva, es un ejemplo de dato que sería importante conocer. Esta instancia es clave porque tiene poder para mejorar las condiciones de trabajo, es fundamental que las mujeres tengan participación, de lo contrario sus reivindicaciones serán ignoradas por espacios de decisión masculinos que difícilmente incorporen cláusulas que equiparen la desigualdad estructural. ${ }^{32}$

Así como se solicita la incorporación de una perspectiva de género sería valioso que la $\mathrm{OC}$ incorpore una perspectiva en migraciones (mejor: una interseccional). Se trata de un colectivo que debe gozar de especial protección (Corte IDH 2003, "OC-18/03") y que es víctima recurrente de abusos laborales. Por ejemplo escrutar si normas como la que impone que un $75 \%$ de los cargos diligénciales y representativos en un sindicato deben ser nacionales argentinos (Ley 23.551; art. 18 c)), es una distinción objetiva y razonable o discriminatoria.

\footnotetext{
31 Aunque parece que su incumplimiento es reiterado. Ver los considerandos de la Disposición 7-E/2017 de la Dirección de Asociaciones Sindicales del Ministerio de Trabajo, Empleo y Seguridad Social, disponible en http://servicios.infoleg.gob.ar/infoleglnternet/ anexos/270000-274999/273395/norma.htm (consultado por última vez el 24/03/2020)

32 En Argentina la ley 25.647 exige que las con participación proporcional de mujeres delegadas a las trabajadoras de la rama o actividad y de lo contrario no les será oponible a las trabajadoras las reformas in peius.
} 
En definitiva, las cuestiones interpretativas que quedan justifican la conveniencia y oportunidad de solicitar la opinión por parte de la $\mathrm{CIDH} .{ }^{33}$

\section{Ideas conclusivas}

Es un principio social aceptado que los/las trabajadores/as asociados en sindicatos, a través de su función de autotutela, obtienen una mejor protección de sus derechos y promoción de sus intereses (Ledesma, 2011; 9).

En esa tarea, las asociaciones sindicales, tienen un importante blindaje jurídico de nivel legal pero también supra legal. Esta situación en cuanto al derecho sustancial se complementa con mecanismos procesales a nivel internacional. A la- ya conocida - protección que les brinda la OIT aquí exponemos que se le suma la del Sistema Interamericano de Derechos Humanos.

Recuperando la idea inicial de climax, los derechos sindicales parecen obtener un lugar de centralidad en los mecanismos de protección de los derechos humanos, cuyos estándares quedarán cristalizados al resolverse la Opinión Consultiva solicitada por la CIDH.

Como es ilusorio suponer que todas las vulneraciones de derechos sindicales podrán tener acogida en el ámbito internacional y que en función del principio de subsidiariedad no sería adecuado, entendemos fundamental la labor de interiorización. Buena parte de la efectividad se juega en los tribunales internos.

En el DCT existe toda una línea jurisprudencial de la CSJN que va en ese sentido. Sin ir más lejos puede considerarse

\footnotetext{
33 Lo anterior considerado desde una perspectiva técnica-jurídica y desde la función cuasi-jurisdiccional o protectoria de la CIDH. Ahora bien, desde una mirada de la promoción 0 política puede pensarse como hipótesis que el Sistema al poner en agenda los derechos de los sindicatos busca ampliar su base de sustentación ya que atraviesa una coyuntura complicada (ver por ejemplo la cuestionada Declaración conjunta de algunos países presentado a la CIDH el 11 de abril de 2019 http://www.minjusticia.gob.cl/comunicado-de-prensa-ministerio-derelaciones-exteriores-ministerio-de-justicia-y-derechos-humanos-sobre-sistema-interamericano-de-derechos-humanos/ recuperado el 24 de marzo de 2020.)
} 
la revolucionaria sentencia que significó el fallo de la Corte Federal en "ATE c. Ministerio de Trabajo" del año 2008 para el "modelo sindical argentino". La estructura conceptual misma que subyace a la regulación jurídica del DCT en nuestro país ha sido puesta en cuestión por una sentencia que contiene una profusa argumentación en derechos humanos.

Este último caso nos demuestra como en el DCT el entrecruzamiento entre derecho constitucional/internacional e infraconstitucional es permanente. Ténganse presente que otros fallos de similar calibre de la CSJN se sucedieron como "Rossi", 2009 y "Álvarez c. Cencosud", 2010. Incluso aunque ahora con un fin restrictivo la CSJN se ve en la necesidad de analizar intensamente el acervo normativo internacional en "Orellano", 2016. ${ }^{34}$

En el futuro deberemos esperar un mayor desarrollo interamericano en la materia (presumible según los avances en materia de justiciabilidad de DESC), atendiendo a su plasmación en nuestro derecho local.

\section{Referencias bibliográficas}

\section{a. Bibliografía}

Afarian, J. (2019). "El fallo "SIPOBA c. Ministerio de Trabajo": Seis errores teórico-conceptuales de la Corte Suprema de Justicia de la Nación y su impacto en la libertad sindical." En Derechos En Acción, 10 (10). https://doi.org/10.24215/25251678e258

Bazán, V. (2011). "Vías de exigibilidad de los derechos económicos, sociales y culturales en los ámbitos interno e interamericano." en Contextos. $N^{o}$ 2. Buenos Aires: Defensoría del Pueblo de la Ciudad de Buenos Aires.

Cabral, P. O. y Schreginger, M. J. (2009) El Régimen de Empleo Público en la Provincia de Buenos Aires. Buenos Aires: Abeledo Perrot.

34 Para una reflexión sobre los últimos pronunciamientos del alto tribunal federal en materia de derecho laboral y su consideración de restrictivos en materia de derechos ver Afarian, 2019 y doctrina citada; 391. 
Catani, E. (2018). "Una aproximación conceptual a la dimensión colectiva del Derecho del Trabajo". En Derechos En Acción, 7 (7). https://doi.org/10.24215/25251678e149

Christian Courtis (compilador) (2006). Ni un paso atrás: la probibición de regresividad en materia de derechos sociales. Ciudad de Buenos Aires: Editorial del Puerto.

Organización Internacional del Trabajo (2018). La libertad Sindical: Recopilación de decisiones del Comité de Libertad Sindical. Sexta ed. Ginebra: OIT. Disponible en https://www.ilo.org/.

CIDH (2019) "Alcance de las obligaciones de los Estados, bajo el Sistema Interamericano, sobre las garantías a la libertad sindical, su relación con otros derechos y aplicación desde una perspectiva de género" presentada en julio. Recuperado de https:// www.corteidh.or.cr/docs/solicitudoc/soc_3_2019_spa.pdf

Cuartango, O.A. y Cuartango G.(2006). El Derecho Colectivo del Trabajo y la Relación de Empleo Público. En BASTONS, J.L. (Dir.) Empleo Público, La Plata: Librería Editorial Platense.

Etala, C.A. (2007). Derecho colectivo del trabajo (2a ed.). Editorial Astrea, Buenos Aires.

Faúndez Ledesma, H (1999). El Sistema Interamericano de Protección de los Derechos Humanos: Aspectos Institucionales y Procesales. Segunda ed. Costa Rica: IIDH.

Ferrer Mac-Gregor, Eduardo; Morales Antoniazzi, Mariela; Flores Pantoja, Rogelio (coordinadores) (2018). La puerta de la justiciabilidad de los derechos económicos, sociales, culturales $y$ ambientales en el Sistema Interamericano: relevancia de la sentencia Lagos del Campo y nuevos desafios. Querétaro, Instituto de estudios constitucionales del Estado de Querétaro.

González Prado, P y Yanes, A (2013) (Coords.) Violencia contra las mujeres: quien calla otorga. Mendoza: IDEGE.

Gonzalo Hancco Suyo (2019). "El derecho social a la libertad sindical: fundamentos y alcances a nivel constitucional e internacional" en Revista Argumentum,20,2.http://ojs.unimar.br/index. $\mathrm{php} /$ revistaargumentum/article/view/1183

Greco, J.J. (2019) "El derecho sindical en el sector público mendocino". Publicado en la Plataforma de información para politicas públicas de la Universidad Nacional de Cuyo. URL 
del artículo http://www.politicaspublicas.uncu.edu.ar/articulos/index/el-derecho-sindical-en-el-sector-publico-mendocino. Recuperado el 23 de noviembre de 2019.

Ledesma,C. Derechos Sindicales en el Sector Publico en América Latina. Centro Internacional de Formación de la Organización Internacional del Trabajo. 2011.

Livellara, Carlos Alberto (Dir.) (2013). Derecho del trabajo y de la seguridad social. Ciudad Autónoma de Buenos Aires: La Ley.

Machado, J D. y Ojeda, R. H. (2006). Tutela Sindical: Estabilidad del representante gremial. Buenos Aires: Rubinzal-Culzoni.

Steiner, C. y Uribe, P. (Eds.)(2014). Convención Americana sobre Derechos Humanos. Comentario. Bolivia: Konrad-AdenauerStiftung.

Wlasic, J. C. (2016). Manual Crítico de Derechos Humanos. ( $1^{\mathrm{a}}$ ed.) Buenos Aires: La Ley.

Zas, O. (2017). "La titularidad del derecho de huelga en la doctrina de la Corte Suprema de Justicia Argentina" en Revista Chilena de Derecho del Trabajo y de la Seguridad Social, 8, 15.

\section{i. Normativa}

Asamblea General de la OEA (17 de noviembre de 1988). Protocolo adicional a la Convención Americana en materia de Derechos Económicos Sociales y Culturales, [Protocolo de San Salvador]. Asamblea General de las Naciones Unidas (10 de diciembre de 1948). Declaración Universal de los Derechos Humanos, [DUDH].

Congreso de la Nación Argentina (14 de abril de 1988), Ley de Asociaciones Sindicales, [No 23.551].

Convención Americana sobre Derechos Humanos (22 de noviembre de 1969), [CADH].

\section{ii. Jurisprudencia}

Corte Interamericana de Derechos Humanos: [Corte IDH]

- 2001. Baena Ricardo y otros Vs. Panamá. Fondo, Reparaciones y Costas. Sentencia de 2 de febrero.

- 2003. Condición jurídica y derechos de los migrantes indocumentados. Opinión Consultiva OC-18/03 de 17 de septiembre. 
- 2005. Caso Huilca Tecse Vs. Perú. Fondo, Reparaciones y Costas. Sentencia de 3 de marzo.

- 2008. Cantoral Huamaní y García Santa Cruz Vs. Perú. Interpretación de la Sentencia de Excepción Preliminar, Fondo, Reparaciones y Costas. Sentencia del 28 de enero.

- 2012. Caso García y familiares Vs. Guatemala. Fondo, Reparaciones y Costas. Sentencia de 29 noviembre.

- 2016. Titularidad de derechos de las personas jurídicas en el Sistema Interamericano de Derechos Humanos. [OC-22/16] de 26 de febrero.

- 2017. Lagos del Campo Vs. Perú. Excepciones Preliminares, Fondo, Reparaciones y Costas. Sentencia de 31 de agosto.

- 2018. Isaza Uribe y otros Vs. Colombia. Fondo, Reparaciones y Costas. Sentencia de 20 de noviembre.

- 2019. Asociación Nacional de Cesantes y Jubilados de la Superintendencia Nacional de Administración Tributaria (ANCEJUBSUNAT) Vs. Perú. Sentencia de 21 de noviembre.

- 2019. Gómez Virula y ot. Vs. Guatemala. Fondo, reparaciones y costas. Sentencia de 21 de noviembre.

Corte Suprema de Justicia de la Nación [CSJN]:

- 2008. "Asociación Trabajadores del Estado c/ Ministerio de Trabajo s/ Ley de Asociaciones Sindicales." Del 11 de noviembre.

- 2016. "Orellano, Francisco Daniel c/ Correo Oficial. Del 7 de junio.

- 2017 "Sala, Milagro Arnalia Ángela y otros s/ asociación ilícita, fraude a la administración pública y extorsión". Del 5 de diciembre.

- 2017 "Ministerio de Relaciones Exteriores y Culto". Del 14 de febrero

- 2019. "Recurso de hecho deducido por la defensa de Roberto Urzagasti, Justo Pastor Leguizamón, Pilar Magdalena Ruiz y Ariel Marcelo Gutiérrez en la causa Farfán, Julio Antonio y otros s/ amenazas agravadas, daños agravados, turbación al ejercicio de la función pública, San Pedro de Jujuy”. Del 16 de abril. 